\title{
MENINOS DO LIMBO: ESCRAVIDÃO, FAIXAS ETÁRIAS E ATRIBUIÇÕES SOCIAIS: SÃO FRANCISCO DE PAULA (1812-
} 1834)

\author{
Rachel dos Santos Marques*
}

Resumo: Este artigo busca discutir a designação social por faixa etária atribuída a jovens escravos nos registros de óbito da Freguesia de São Francisco de Paula (atual Pelotas-RS) entre os anos de 1812 e 1834. Nos registros referidos, pessoas com até oito anos de idade foram designadas enquanto "inocentes", e pessoas com quatorze anos ou mais são referidas enquanto "solteiro", "casado" ou "viúvo" (termos interpretados como referindo-se a pessoas adultas). Entretanto, pessoas entre as idades de 9 e 13 anos carecem de qualquer designação. Isso pode indicar certa indefinição quanto a sua posição social (em termos etários). Foi feita também uma breve comparação com designações encontradas nos registros de óbitos de livres, por meio da qual perceberam-se algumas diferenciações que podem lançar luz sobre a funcionalidade dessas designações.

Palavras-chave: escravidão, designação social.

* Doutoranda em História pela Universidade Federal do Paraná. Bolsista
CAPES/REUNI. Contato: rachelsmarques@gmail.com 
Abstract: This article discusses the social designation assigned by age to young slaves in death certificates of the Parish of St. Francis of Paula (current Pelotas-RS) between the years 1812 and 1834. In these records, people with up to eight years of age were designated as "innocent", and people that were fourteen years old or older awere referred to as "single", "married" or "widower" (interpreted as terms referring to adult). However, people between the ages of 9 and 13 lack any designation. This may indicate some uncertainty as to their social position (in terms of age). A brief comparison was made with designations found in the death records of free people, through which some differences were perceived that may shed some light on the functionality of these designations.

Keywords: slavery, social designation

Durante o percurso de uma pesquisa os historiadores frequentemente encontram muito mais perguntas do que respostas. Os procedimentos de pesquisa, os estudos realizados, o trabalho com as fontes fornecem cada vez mais perguntas, muitas delas não sendo perseguidas no momento em que surgem por falta de tempo, de possibilidade, ou por saírem do escopo da pesquisa já em andamento.

No transcorrer de uma pesquisa realizada para a produção do Trabalho de Conclusão de Curso, requisito para o recebimento do título de Licenciada em História, a presente autora deparou-se com alguns 
elementos presentes na documentação analisada que geraram perguntas que não puderam ser enfocadas no momento citado. Tais perguntas e os primeiros resultados obtidos a partir delas serão apresentadas no presente artigo, com o intuito de instigar os pesquisadores a novas possibilidades de trabalho surgidas em elementos muitas vezes deixados de lado na documentação por seu caráter circunstancial.

A pesquisa original tratava da mortalidade de inocentes escravos na Freguesia de São Francisco de Paula, onde se encontra atualmente a Cidade de Pelotas (Rio Grande do Sul), entre os anos de 1812 - ano inaugural da Freguesia, e, portanto dos registros paroquiais a ela relacionados - e 1834 - ano anterior à deflagração da Revolução Farroupilha, evento que desorganizou em muitos aspectos a sociedade sul-rio-grandense, o que se reflete na documentação que trata de sua população. Utilizou-se como fonte principal registros de óbito de escravos da freguesia ${ }^{1}$.

A existência dos Registros Paroquiais é fruto da disposição da Igreja Católica de efetuar um melhor controle de seus fiéis, que se traduziu, principalmente, a partir do Concílio de Trento, em uma série de normas a serem cumpridas por párocos e fiéis. Entre essas normas

\footnotetext{
ARQUIVO DA CÚRIA DIOCESANA DE PELOTAS. $1^{\circ}$ livro de Óbitos de Escravos da Freguesia de São Francisco de Paula (1812-1846).
} 
estava a padronização dos registros dos principais sacramentos católicos. Na América Portuguesa, as determinações do Concílio de Trento foram adaptadas pelas Constituições Primeiras do Arcebispado da Bahia ${ }^{2}$. Segundo tais ordenações, em cada paróquia deveriam existir livros, encadernados e numerados, que dessem conta do registro dos sacramentos, dentre os quais os principais eram os batismos, os casamentos e o assento dos óbitos.

Nas constituições também ficavam designados alguns parâmetros para a feitura dos registros em si. Os assentos de óbitos eram feitos principalmente para registrar os sacramentos dados àqueles próximos da morte e as encomendações feitas aos falecidos, e também como forma de controle de que tudo tenha ocorrido de acordo com as disposições. Deveriam ser feitos da maneira seguinte:

Em todas as Igrejas Paroquiais deve haver livro em que se assentem os nomes dos defuntos, o que se introduziu por muitas razões convenientes. Por tanto mandamos, que em todas as Igrejas Paroquiais haja um livro em que se assentem os nomes dos que morrerem, \& que cada hum dos Párocos de nosso Arcebispado no dia em que o defunto falecer, ou ao mais tardar dentro dos três primeiros seguintes, faça no dito livro assento do seu

${ }^{2}$ DA VIDE, Sebastião Monteiro. Constituições Primeiras do Arcebispado da Bahia. Coimbra: Colégio das Artes da Compahia de Jesus, 1707. 
falecimento, escrevendo-o ao comprido, \& não por abreviatura, ou algarismo, de maneira seguinte.

Aos tantos dias de tal mês, \& de tal ano faleceu da vida presente N. Sacerdote, Diácono, ou Subdiácono ; ou N. marido, ou mulher de $\mathrm{N}$. ou viúvo, ou viúva de $\mathrm{N}$. ou filho, ou filha de N. do lugar de N. freguês desta, ou de tal Igreja, ou forasteiro, de idade de tantos anos, (se comodamente se puder saber) com todos, ou tal Sacramento, ou sem eles : foi sepultado nesta, ou em tal Igreja : fez testamento, em que deixou se dissessem tantas Missas por sua alma, \& que se fizessem tantos Ofícios; ou morreu ab intestado, ou era notoriamente pobre, \& por tanto se lhe fez o enterro sem se lhe levar esmola3

No entanto, notou-se uma disparidade muito grande no conteúdo dos registros trabalhados. Essas diferenças foram encontradas à medida que os anos nos registros iam avançando, principalmente com a mudança dos párocos, mas não apenas. Em vinte e dois anos encontraram-se seis Vigários e nove alternâncias, já que pelo menos dois deles eram vigários encomendados, ou seja, eram nomeados com tempo determinado, geralmente a pedido do povo ${ }^{4}$.

Embora os registros paroquiais existentes dificilmente sigam o padrão estabelecido nas Constituições, trazem informações em massa

${ }^{3}$ DA VIDE, Sebastião Monteiro. Constituições Primeiras do Arcebispado da Bahia. Coimbra: Colégio das Artes da Compahia de Jesus, 1707. Grafia por mim atualizada.

${ }^{4}$ RUBERT, Arlindo. História da Igreja no Rio Grande do Sul: época colonial. Porto Alegre: EDIPUCRS, 1994. 
acerca dos agentes do passado que muito raramente são encontradas em outras fontes. Não estão livres, no entanto, de limitações. A referida falta de uniformidade na feitura dos registros pode dificultar a realização de certas análises por um largo período, ou mesmo a comparação de um mesmo aspecto em localidades diferentes. Tem-se como exemplo disso o fato de que nem todos os padres anotavam a causa-mortis nos registros de óbito, ou não a anotavam para todas as pessoas, como foi verificado por diversos autores que trabalham com o estudo da mortalidade na América Portuguesa (FARIA, 1998; BECKER, 2010; ALMEIDA, 2012; entre outros). ${ }^{5}$

Além da falta de uniformidade em si, existe o problema de que os registros eclesiásticos nem sempre abarcam a população uniformemente. Isso não diz respeito apenas aos sub-registros, mas também a uma série de clivagens inerentes a esse tipo de fonte. A primeira delas se dá em função do catolicismo em si: a sociedade estudada era oficialmente católica, no entanto, nem todos os seus

\footnotetext{
${ }^{5}$ FARIA, Sheila de Castro. Família e morte entre escravos. In: XI Encontro Nacional de Estudos Populacionais, 1998, Caxambu. Anais do XI Encontro Nacional de Estudos Populacionais. Caxambu : ABEP, 1998 pp. 1273-1298.; ALMEIDA, Ana Maria Leal. Doenças/causa-mortis dos escravos em Vassouras. Anais do III Encontro Nacional de Ciências da Saúde e do Ambiente. Niterói, 2012.; BECKER, Carolina Bitencourt. Os escravos e sua relação com a história da saúde na fronteira meridional do Rio Grande do Sul do século xix. X Encontro Estadual de História: ANPUH-RS, 2010.
} 
membros o eram, o que faz com que uma grande parcela da população notadamente os indígenas não-convertidos - não esteja contemplada nessa documentação.

Se a importância social e espiritual de um sacramento como o batismo, por exemplo, fazia com que o mesmo fosse realizado numa parcela mais ampla da sociedade, o mesmo não acontecia para casamentos e óbitos. Com relação aos óbitos, o problema se agrava, uma vez que o sepultamento de um falecido não ocorria necessariamente dentro de um cemitério de uma paróquia, e de acordo com os preceitos cristãos - o que fazia com que nem sempre fosse registrado. Ainda assim, nem sempre isso resultava na existência de sub-registros: muitas mortes ocorridas sem o devido sacramento foram posteriormente referidas nos livros de registros de óbitos ${ }^{6}$.

Nos registros de óbito existentes referentes à Freguesia de São Francisco de Paula - que existem para o período de 1812 a 1887 - os que menos informações traziam constavam o nome do falecido, a data do registro, o nome do dono e o local de sepultamento. A maioria dos registros informava também a idade, a nação do escravo, se era casado, solteiro ou viúvo - em se tratando de adultos -, a causa da morte, se

\footnotetext{
${ }^{6}$ ARQUIVO DA CÚRIA DIOCESANA DE PELOTAS. $1^{\circ}$ livro de Óbitos de Escravos da Freguesia de São Francisco de Paula, 1812-1846.
} 
recebeu os devidos sacramentos e o local de sepultamento. Talvez os registros mais completos sejam aqueles que dizem respeito aos inocentes crioulos, já que informavam, geralmente, mas nem sempre, também o nome da mãe e, quando se tratava de filhos legítimos, o nome do pai. $\mathrm{O}$ mesmo não se dava com os inocentes africanos, que eram poucos e cujos registros poucas informações traziam.

De forma geral, no entanto, o primeiro livro de óbitos de escravos de São Francisco de Paula traz informações bem completas, excetuando-se o período que vai de fevereiro a dezembro de 1830, no qual nenhum registro foi feito. Esse fato foi registrado pelo padre Visitador que, em 24 de julho de 1832, escreveu o seguinte:

Vejo em visita. Não aparece neste livro acento algum lavrado pelo Reverendo Padre Manoel Antônio de Azevedo no decurso de um ano e ainda mais; o [quanto] notável não ter falecido nesta freguesia escravo algum; da sorte que quando sendo preciso alguma certidão á algum freguês de óbito de algum escravo então falecido, não se lhe poderá dar pela [ilegível] do livro do dito Reverendo Padre Abade Manoel Antônio de Azevedo. Cumpre por tanto a [ilegível] desta visita no livro dos óbitos das pessoas livres as folhas cento e quarenta e nove, visto. 
Villa de S. Franco de Paula de Pelotas 24 de Julho de 1832. [assinatura ilegível]"7

Além dessas questões, mesmo os registros mais completos apresentam alguns problemas, os quais o pesquisador deve ficar atento. Um deles é o fato de que as idades que aparecem nos registros são, provavelmente, aproximadas. Isso fica explícito quando encontram-se expressões como "que parecia ter quarenta anos", "mais de cinquenta anos", "vinte e tantos anos", "trinta e cinco anos mais ou menos", entre outras. Porém, o grande número de arredondamentos pode indicar que mesmo as idades explícitas não eram exatas. Cerca de $76 \%$ das idades de adultos encontradas terminam em zero ou cinco.

Sobre as idades, percebeu-se a existência, de maneira geral, de diferentes tipos de atribuições ou designações a três diferentes faixas etárias: pessoas com até 8 anos eram ditas inocente, criolinho(a), ou pardinho(a); a pessoas com quatorze anos ou mais eram atribuídos o que seria hoje chamado de estado civil, ou seja, casado(a), solteiro(a) ou viúvo(a); pessoas entre nove e treze anos, entretanto, não possuíam qualquer designação.

7 ARQUIVO DA CÚRIA DIOCESANA DE PELOTAS. $1^{\circ}$ livro de Óbitos de Escravos da Freguesia de São Francisco de Paula, 1812-1846, p. 146. Grafia por mim atualizada. 
Assim, para o período e local designados tem-se de um total de 1443 registros de óbitos de escravos. Destes, em 105 (7,2\%) casos não constava a idade ou a mesma estava ilegível, 377 (26,1\%) eram inocentes, $934(64,7 \%)$ adultos e $27(1,87)$ constavam nesta faixa etária que prescinde de qualquer designação.

O termo inocente era utilizado pela igreja para designar pessoas que já receberam o batismo, mas que ainda não fizeram a primeira comunhão, momento a partir do qual o fiel tornar-se-ia responsável por sua vida espiritual (até tal momento é ao padrinho do inocente que cabe essa responsabilidade). A idade recomendada para a primeira comunhão é a de sete anos, ainda que ela nem sempre fosse feita nessa idade. Nos registros trabalhados, as pessoas falecidas com até oito anos também eram designadas inocentes. Os termos crioulinho(a) e pardinho(a) apareciam sempre associados também a falecidos com idades entre zero e oito anos. Quanto aos registros que continham as designações casado(a), solteiro(a), e viúvo(a), entende-se os mesmos como tratando de pessoas adultas, uma vez que tais designações fossem encontradas sempre relacionadas a pessoas com quatorze anos ou mais. Essa idade era considerada a idade do juízo, pelo menos com relação aos homens. Às mulheres era permitido casar a partir dos doze anos de idade, e aos homens, a partir dos quatorze. Também eram as idades em se tornava 
obrigatório receber o sacramento da eucaristia, respectivamente para mulheres e homens, segundo as Constituições:

Posto que este Sacramento não seja necessário como meio preciso à salvação, contudo, conforme a disposição dos Sagrados Cânones, e Concílio Tridentino, todos os fiéis Cristãos de um, e outro sexo, tanto que chegarem aos anos da discrição, que nos homens regularmente são os quatorze, e nas mulheres os doze, e tiverem juízo para entenderem o que fazem, e a reverência que se deve a este Divino Sacramento, que bem pode ser se antecipe nos homens, mais que nas mulheres, antes dos quatorze, e dos doze, o que prudentemente julgará o Pároco, são obrigados a receber, ao menos uma vez a cada ano pela Páscoa da Ressurreição. ${ }^{8}$

A idade de 14 anos também era referência ao gozo do juízo em documentos seculares, como demonstra o exemplo encontrado no testamento de João Duarte Machado, habitante da localidade pesquisada, onde se lê:

Eu Escrivão aprovador aceitei e aprovei tudo quanto devo por bem do meu ofício, rubriquei as folhas dele com minha rubrica que diz $=$ Torres $=$ e o testador se assinou

${ }^{8}$ DA VIDE, Sebastião Monteiro. Constituições Primeiras do Arcebispado da Bahia. Coimbra: Colégio das Artes da Compahia de Jesus, 1707. Grafia por mim atualizada. 
com cinco testemunhas todas livres de maior idade de quatorze anos ${ }^{9}$

Ainda que para as mulheres a idade da razão citada seja a de doze anos, nos registros trabalhados em nenhum momento os termos solteira, casada, ou viúva foram atribuídas a mulheres com menos de quatorze anos, o que sugere ser esta a idade considerada como fronteira que marca o início da vida adulta, pelo menos em São Francisco de Paula de Pelotas nas primeiras décadas do século XIX.

Levando em consideração o que foi dito acima, percebe-se que a ausência de quaisquer designações acompanhando o nome de pessoas que faleceram na faixa entre nove e treze anos pode sugerir certa indefinição quanto à maneira com que essa sociedade percebia tais pessoas. O diminuto número de casos encontrados também pode ser significativo se comparado com grande número de óbitos encontrados referentes a pessoas com as idades de oito e quatorze anos. A quantidade de casos sugere que os arredondamentos aconteciam não apenas com as idades dos adultos (que tendiam a terminar com zero e

\footnotetext{
${ }^{9}$ ARQUIVO PÚBLICO DO ESTADO DO RIO GRANDE DO SUL, INVENTÁRIO de João Duarte Machado, 1828, Pelotas, $1^{\circ}$ Cartório de Órfãos e Provedoria, E 40, M10, N 123. Grafia por mim atualizada.
} 
Revista Vernáculo, $n^{\circ} 29,1^{\circ}$ sem/2012

cinco), mas também nessas duas idades, entendidas aqui como marcos até 8 anos marcadamente inocentes, crioulinhos ou pardinhos, acima de quatorze anos tratava-se de adultos.

Dado o pequeno escopo da investigação inicial, tais hipóteses necessitam, ainda, serem testadas em contextos diferentes para serem verificadas. Um passo nesse sentido foi dado com uma breve análise dos registros referentes à população livre da mesma localidade no período de 1812 a $1818 .{ }^{10}$

A maior diferença até agora encontrada foi a ausência de designação do tipo encontrado para escravos (inocente, solteiro, casado ou viúvo) no corpo no registro. Dos 77 casos, em apenas sete constava a designação "inocente" (todos com idade igual ou inferior a oito anos), e em apenas um caso a designação "solteira" (treze anos). Nos 69 restantes constavam as designações "filho legítimo de" "filho natural de" "exposto em casa de" e "escrava que foi de". Aspecto diferente encontra-se ao observar os escritos à margem dos registros: em um dos registros a margem estava ilegível, e não pôde ser identificada; em sete casos apenas constava o nome do falecido; em 55 ocorrências apareciam juntamente ao nome o termo inocente; e, três constava o

\footnotetext{
10 ARQUIVO DA CÚRIA DIOCESANA DE PELOTAS. $1^{\circ}$ livro de Óbitos da Freguesia de São Francisco de Paula, 1812-1846.
} 
nome a alguma designação de cor (respectivamente pardo, crioulo e negra); em oito casos na margem aparecia o termo "solteiro"; e em três aparecia o nome do falecido seguido de "filho de" e o nome do pai.

A primeira questão a ser discutida é a inexistência do "limbo" etário - aqueles que não são inocentes, são solteiros. A segunda é que as designações etárias, nos registros de livres, parecem estar "em segundo plano" - nos registros de escravos as mesmas apareciam tanto no corpo do texto quanto na margem, enquanto nos registros de livres apenas nas margens. Considerando que os párocos que fizeram os registros são os mesmos, e que se trata de uma mesma localidade e um mesmo período, essa diferença pode ser significativa.

Parece ser mais importante, portanto, localizar com precisão a faixa etária a que pertencia um jovem escravo do que aquela a que pertencia um jovem livre. Esse fator está ligado, muito provavelmente, ao papel do escravo nessa sociedade. Não apenas a idade do escravo influenciava em muito seu valor de venda, como os escravos considerados adultos poderiam ser vendidos separadamente de suas mães com menores constrangimentos por parte da Igreja, que condenava a separação de famílias. ${ }^{11}$

\footnotetext{
${ }^{11}$ Tal separação só foi oficialmente proibida pelo decreto $\mathrm{n}^{\circ} .1695$, de 15 de setembro de 1869, do Império Brasileiro.
} 
Manolo Florentino e José Roberto Góes, analisando o contexto do Rio de Janeiro, observaram que

\begin{abstract}
Por volta dos 12 anos, o adestramento que as tornava adultos estava se concluindo. Examinando as listas de escravos dos inventários post-mortem de 1790 a 1835 , observa-se que era nesta idade que os meninos e as meninas começavam a trazer a profissão por sobrenome: Chico roça, João pastor, Ana mucama. Alguns haviam começado muito cedo. O pequeno Gastão, por exemplo, aos quatro anos já desempenhava tarefas domésticas leves na fazenda de José de Araújo Rangel. Gastão nem bem se pusera de pé e á tinha um senhor. Manoel, aos oito nos, já pastoreava o gado na fazenda de Guaxindiba, pertencente à baronesa de Macaé, e de Rosa, escrava de Josefa Maria Viana, aos 11 anos de idade dizia-se ser costureira. Aos 14 anos, era-se um adulto completo. ${ }^{12}$
\end{abstract}

O possível arredondamento de idades de falecidos escravos nas idades de oito e quatorze anos, observado no caso da Freguesia de São Francisco de Paula de Pelotas coloca em evidência uma possível necessidade de estipular com clareza o grupo a que pertenciam essas pessoas, e o "limbo" etário existente entre nove e treze anos, evidencia a dificuldade de definir, socialmente, como seriam classificadas pessoas

${ }^{12}$ FLORENTINO, Manolo e GÓES, José Roberto. Morfologias da criança escrava: Rio de Janeiro, séculos XVIII e XIX. In: FLORENTINO, Manolo (Org). Tráfico, cativeiro e liberdade (Rio de Janero, séculos XVII-XIX). Rio de Janeiro: Civilização Brasileira, 2005, p. 217. 
que não eram mais crianças (inocentes, pela igreja, ainda não responsáveis pela sua vida espiritual) mas ainda não eram adultos (ainda não poderiam casar, no caso dos homens). Tais questões podem se mostrar importantes na investigação e na compreensão do aparecimento conceitos tais como infância e juventude.

É preciso, no entanto, ampliar em muito a pesquisa para que melhores resultados possam ser alcançados. Como foi dito no início do artigo, as considerações aqui feitas partem de elementos circunstanciais, uma vez que levam em consideração apenas uma freguesia, em um período curto de tempo. Para que mais possa ser dito é preciso ampliar o escopo da pesquisa.

A validade da discussão está, acredita-se, em perceber novas maneiras de trabalhar uma documentação já bastante utilizada com outros intuitos, e em utilizar indícios não ortodoxos na tentativa de elucidar questões difíceis de serem trabalhadas com relação a determinados períodos. Nas palavras de Carlo Ginzburg:

Mesmo que o historiador não possa deixar de se referir, explícita ou implicitamente, a séries de fenômenos comparáveis, a sua estratégia cognoscitiva assim como os seus códigos expressivos permanecem intrinsecamente individualizantes (mesmo que o indivíduo seja talvez um grupo social ou uma sociedade inteira). Nesse sentido, o historiador é comparável ao médico, que utiliza os 
quadros nosográficos para analisar o mal específico de cada doente. E, como o do médico, o conhecimento histórico é indireto, indiciário, conjetural. ${ }^{13}$

Finaliza-se o presente artigo com a sugestão para que antigos e novos historiadores repensem categorias já firmadas, observem elementos a primeira vista negligenciáveis na documentação com a qual trabalham. E também com a esperança de ter-se podido contribuir, ainda que timidamente, com o conhecimento que vamos construindo, dia após dia, do passado.

GINZBURG, Carlo. Sinais: Raízes de um paradigma indiciário. In: GINZBURG, Carlo. Mitos, emblemas e sinais. São Paulo: Cia das Letras, 1989, pp. 143-179. 


\section{Fontes Manuscritas}

ARQUIVO DA CÚRIA DIOCESANA DE PELOTAS. $1^{\circ}$ livro de Óbitos da Freguesia de São Francisco de Paula, 1812-1846.

ARQUIVO DA CÚRIA DIOCESANA DE PELOTAS. $1^{\circ}$ livro de Óbitos de Escravos da Freguesia de São Francisco de Paula (18121846).

ARQUIVO PÚBLICO DO ESTADO DO RIO GRANDE DO SUL, INVENTÁRIO de João Duarte Machado, 1828, Pelotas, $1^{\circ}$ Cartório de Órfãos e Provedoria, E 40, M10, N 123.

\section{Fontes impressas}

DA VIDE, Sebastião Monteiro. Constituições Primeiras do Arcebispado da Bahia. Coimbra: Colégio das Artes da Compahia de Jesus, 1707.

\section{Referências}

ALMEIDA, Ana Maria Leal. Doenças/causa-mortis dos escravos em Vassouras. Anais do III Encontro Nacional de Ciências da Saúde e do Ambiente. Niterói, 2012.

BECKER, Carolina Bitencourt. Os escravos e sua relação com a história da saúde na fronteira meridional do Rio Grande do Sul do século xix. X Encontro Estadual de História: ANPUH-RS, 2010. 
Revista Vernáculo, $n^{o} 29,1^{o}$ sem/2012

FARIA, Sheila de Castro. Família e morte entre escravos. In: XI Encontro Nacional de Estudos Populacionais, 1998, Caxambu. Anais do XI Encontro Nacional de Estudos Populacionais. Caxambu : ABEP, 1998 pp. 1273-1298.

FLORENTINO, Manolo e GÓES, José Roberto. Morfologias da criança escrava: Rio de Janeiro, séculos XVIII e XIX. In: FLORENTINO, Manolo (Org). Tráfico, cativeiro e liberdade (Rio de Janero, séculos XVII-XIX). Rio de Janeiro: Civilização Brasileira, 2005, PP. 207-227.

GINZBURG, Carlo. Sinais: Raízes de um paradigma indiciário. In: GINZBURG, Carlo. Mitos, emblemas e sinais. São Paulo: Cia das Letras, 1989, pp. 143-179.

RUBERT, Arlindo. História da Igreja no Rio Grande do Sul: época colonial. Porto Alegre: EDIPUCRS, 1994. 